\title{
Editorial: A Set of Very Rare Talents
}

In 1947 Wittgenstein wrote that Mahler's music was worthless, and wondered what ought to be done with his talent. 'It took a set of very rare talents to produce this bad music.' In our post-Bernstein, post-Karajan, post-Tennstedt days, this opinion - and from someone to whose childhood home Mahler had been a visitor might seem to verge on the unbalanced. It may have been, but actually in 1947 it would have been by no means unusual (which some commentators on this opinion of Wittgenstein's seem not to realise).

Mahler's music was not performed much in the period in which Wittgenstein was writing, and when it was, it was often to lukewarm or even hostile response. The first complete cycle of Mahler's symphonies after the war took place in London as late as 1959-60. Even then Deryck Cooke, Mahler's great advocate at the time and the completer of the Tenth Symphony, was telling us that the first movement of the Third Symphony was a complete failure. (Maybe a failure only a set of very rare talents could produce, or maybe something only a very rare conducting talent can bring off!) And Antony Hopkins, whose Talking About Music programmes on the BBC were hugely influential in introducing people to classical music in the 1950s, and who loved Richard Strauss, was highly disparaging about Mahler.

Philosophers may feel uncomfortable about applying the changes of fashion, taste and estimation implicit in Wittgenstein's remark to their own subject, salutary though it might be. But what about the other thought, that only a set of very rare talents could produce such bad stuff and bad stuff of this type? Might this thought apply to philosophy?

Whether one agrees with Wittgenstein about Mahler or not - and even as one is overwhelmed by a performance of, let's say, the Third Symphony, one can see what Wittgenstein was getting at, precisely the way one is overwhelmed by material verging at times on the banal - what is not in doubt is that Mahler's music speaks to the ordinary person. It is not music for specialists. By contrast philosophy these days, or at least the most prestigious philosophy, tends to be very much for specialists. So Mahler's special talent and philosophical talent are pulling in contrary directions.

Almost by definition, philosophical talent, in the sense we are considering, is rare, and also rarefied. It requires training and immersion 


\section{Editorial}

in very specialised skills, and speaks to a small, specialised community. Talent and ability are there in abundance; at times one can only gasp in astonishment at the performances, and wonder how it is done. But at times, too, one might wonder at the worth of what is produced, as it disappears into some technical stratosphere. Talent may not be enough. Is it completely wrong in philosophy, sometimes, to yearn for a less talented approach, for one more in touch with the thoughts and concerns of the very people Mahler's music speaks to, the earnest, even passionate enthusiasts of all ages and incomes, who regularly fill out the concerts of his music? But, naturally, it would be said, it must, at all costs, avoid Mahlerian vulgarity... 